\title{
Jankélévitch e os Opostos Sonoros em Harmonia
}

\author{
José Eduardo Martins
}

Correntes analíticas, estudos visando ao conhecimento mais minucioso de um compositor, de suas técnicas, visões e concretudes traduzem parte da decifração da partitura musical. Se há predominância atual para as análises herméticas, exegéticas e estruturais desviando-se, hélas, em sua maioria, do debate das idéias; o debruçar sobre a produção de um criador, em mínimos pormenores, ao menos desvela, sob égide outra, analítica, mananciais que levam à comparação.

A trajetória de um compositor não se faz isolada, mas através das ascendências por ele eleitas e do embasamento pleno, que a partir do acionamento da idéia leva à criação, a transitar se considerado for o longo trilhar que só o intérprete, sempre temporário, pode dar à obra fixada no papel pautado. Este é o porto derradeiro da idéia do compositor e as figuras nele contidas formam o retrato, os traços marcantes nos quais se vislumbram a exterioridade e a interioridade, a hesitação e a certeza, os vestígios dos predecessores admirados e dos coetâneos, as mutações do próprio autor no longo percurso, o homem e suas culturas e, imperativo, o talento, salvaguarda da perenidade da obra de arte. O todo presta-se, quando de um dos compartimentos analíticos - o da comparatividade competente - ao amplo exercício do pensar.

O debruçar comparativo teria basicamente duas correntes, uma objetiva, a partir unicamente das possibilidades dos confrontos entre 
as partituras do compositor, assim como a de seus ascendentes ou coevos, atendo-se o estudioso às estruturas do texto musical; e uma segunda, mais polêmica, em que o pesquisador, por meio do cotejamento, dá asas à imaginação e viaja. O subjetivo podendo suscitar ou a permanência da narração oral interpretativa, sacralizada, na qual as aproximações se fundamentam no real nebuloso e na lenda, ou a recriação interpretativa das imagens e dos símbolos.

Vladimir Jankélévitch insere-se nesta segunda via subjetiva, criando um imaginário diferenciado. Há que se entendê-lo com cautela. Os seus textos sobre música são sobremaneira sedutores, a possibilitarem um descortino outro. Polêmicos, é certo, pois todo um referencial recriado sob a influência do pensador, frise-se, propicia um novo approach quanto às vertentes subjetivas da partitura. Sem jamais se ater às exegéticas correntes analíticas dissecadoras em suas estatísticas, menos ainda aos fatos da trajetória real de um compositor ou as tradicionalizadas histórias de uma obra, está o filósofo-musicólogo a pairar nas sensíveis ambigüidades, buscando reflexões no nível dos antagonismos em torno do inefável, paradoxalmente tornando próximos o texto literário-musical e o objeto essencial, a partitura, princípio absoluto do decorrente.

Haveria, perene, o momento preciso para o compositor no ato da criação, perdido para o jamais em quaisquer avaliações musicológicas pósteras, sendo que as interpretações em nível da escuta estariam a testemunhar a imprecisão constante da partitura precisa, a tornar o resultado sonoro por mais preciso, impreciso.

O preciso-impreciso do discurso hipotético imaginativo de Jankélévitch recupera a certeza, a segurança até, de que o espaço movediço das imagens, no qual se instala, contém a possibilidade do entendimento da gestação idéia-criação através do inefável. Tem o filósofo a temeridade de provocar a criação musical em um de seus fundamentos essenciais, o resultado sonoro, suas origens originárias na idéia do compositor, sejam elas descritivas, onomatopaicas, abstratas, despertando a imaginação do ouvinte, estudioso ou não, através da associação. 
Mune-se Jankélévitch do entender filosófico, da visão poéti$\mathrm{ca}$, do extramusical e, sobremaneira, imperativa, única, não transferível nesse momento exclusivo e individual: a escuta sensível. Os ouvidos, esses órgãos superlativos, despertam o universo associativo e mesmo - por que não? - visionário, por vezes, sobremaneira quando o pensador deriva para o caleidoscópico. Os eleitos, Jankélévitch os conhece, mercê do seu ecletismo e de seu ferramental ligado à música. Para tanto, percebe na exegese do texto musical a trajetória de todos os envolvidos. É cúmplice. A partir, edificará as comparações, as imagens, os símbolos, as metáforas...

Em seus textos sobre música, Vladimir Jankélévitch, naturalmente, sem qualquer empáfia, instaura o peso decisivo de seu apreender filosófico, do professor aberto ao diálogo em quase todos os campos do pensar humanístico - não fique esquecido o não-perdão à Alemanha e ao seu povo após o holocausto, e a não-possibilidade de discussão visando a um novo descortino - do amante profundo da música romântica com a qual se identifica.

As precisas reflexões do autor de Le Pur et l'Impur no vasto campo da imprecisão traduzem-se no emprego de terminologia singular, preferencialmente nos antagonismos das palavras. Servirse-ia de um vocabulário repetitivo à la manière de leit-motifs, palavras que definiriam o não-definível: imponderável, inexprimível, insondável, indefinível, inaudivel, imprevisível, inevidente, indizível, inefável... Esse glossário será, para Jankélévitch, fundamental para a constante formulação de hipóteses em forma discursiva sempre poética, a propiciar ao estudioso não a possibilidade da dúvida mas o brouillard que pode levar ao desvelamento da obra. A criação musical deixando, pois, de ser interpretada sonoramente mas sim através da leitura auditiva, resultando a captação das idéias, transfiguradas, diga-se, vertendo o filósofo para o papel o imaginável possivel.

Antagoniza-se a sua categoria de subjetiva análise - e esse fato é transparente, sob outra égide - daquelas cada vez mais freqüentadas, sobremaneira nos Estados Unidos, dissecadoras, 
anatômicas, que se fundamentam em teorias criadas por musicólogos, a cada período mais complexas em suas estruturas numéricas e estatísticas, mas incensadas por legiões de seguidores. A obra de arte, a partitura, passa a ser interpretada a partir de formulações que jamais o compositor em seu instante final da fixação pensaria, no que se refere àqueles que viveram dos séculos anteriores aos anos 50 deste. Jankélévitch passaria ao largo de todas as teorias gráficas, numerológicas e estatísticas, permanecendo fiel às suas reflexões, conseguindo dar ao texto literário-musical a flexibilização sonora inteirada ao discurso musical; buscando razões detectáveis auxiliadoras naquilo que é a essência plena e ontológica da música: o ouvir.

Vladimir Jankélévitch não foi intérprete executante musical. Ilustrava ao piano os resultados conceituais. A transmissão comparativa de seus textos tem a salvaguarda do vasto conhecimento humanístico.

É possível entender o vazamento constante filosofia-música ou, em outra postura, compreender o amálgama entre as duas áreas do conhecimento. Observa-se que não há a des-seqüência de Jankélévitch ao passar de uma área a outra. Ruptura sim, e, quando ocorre, definitiva. $\mathrm{O}$ extraordinário repertorial filosófico musical alemão abandonado para sempre no não-perdão aos acontecimentos que levaram ao extermínio de milhões de judeus. Opção. Contudo, o anátema por ele lançado retirou de seus textos - é de se lamentar menção à cultuîa germânica. Convicção nesse delicado mister que impediu, é bom lembrar, que comparações suas, que seriam valoradas, entre as seqüências do romantismo musical da Alemanha, fossem feitas em relação às tendências francesas, russas ou ibéricas ${ }^{1}$.

No campo da filosofia, o seu debruçar sobre Bergson deixou profundas raízes. Jankélévitch redimensiona a problemática da duração a partir das categorias rígidas do tempo, entenda-se, sob a égide do universo musical-simbólico. Este seria o eixo paradigmático de todo o seu pensar musical. Em torno do tempo, em seus livros sobre música há reflexões desde a inércia que leva à aceleração, à estagnação, ao ínfimo movimento, à vida e à mor- 
te, ao geotropismo e ao heliotropismo, às dinâmicas inaudíveis ou ao esplendor sonoro, do silêncio... ao silêncio. Essa obsessão com o tempo, a traduzir símbolos e metáforas em constante ambigüidade, possibilita a abertura. Não há confronto como na dialética hegeliana, mas o acordo dos contrários, a cumplicidade dos extremos, a certeza de que sem estes as limitações se darão. A abertura é, pois, fruto desse entendimento que se torna elástico, e quão mais distendido for, maiores as opções da compreensibilidade.

Seguindo-se as sendas dos textos de Jankélévitch sobre música, pareceria nítido um longo erigir conceitual, a partir de percepções mais descritivas e programáticas em seus escritos do final da década de 30. A pesquisa sobre Gabriel Fauré será sistematicamente elaborada, desde Gabriel Fauré et ses mélodies (France, Plon, 1938) até Fauré et l'inexprimable (France, Plon, 1974), obra aumentada, reestruturada, contendo textos inéditos em sua edição definitiva. Há coerência, porém, detecta-se nos textos inseridos nesta última, a presença de metáforas e símbolos que, dos anos 60 à morte, em 85, evidenciam-se onipresentes, poéticos e volatizados.

É o simbólico para Jankélévitch esse universo em expansão? É-o na medida em que o pensador inclui o pensamento rigorosamente singular, visando à interpretação dos compositores estudados em esferas subjetivas, "isolado entre seus colegas e adorado pelos estudantes, 'Janké' foi um contestador modelo"2; é-o na proporção das sonoridades advindas do texto literário amalgamado ao já criado musical. Como não apreender o imaginário sonorosimbólico através da comparação que se dilata a outros gêneros no caso, obras para piano de Fauré? "A obra de Fauré, em sendo inteiramente Nocturne, assim como Berceuse por um de seus aspectos, é, em outro sentido, totalmente Barcarolle pela sua ligação à flexível curvatura dos ritmos compostos: 6/8, 9/8, 12/8 e mesmo 15/8! Se bem que, em definitivo, Barcarolle, Berceuse e Nocturne representem três formas de uma mesma realidade espiritual, três faces de uma mesma paz...".3 
Ao debruçar-se sobre Ravel (Maurice Ravel, Paris, Rieder, 1939), fá-lo, e muito, sob o impacto do virtuosismo musical. Se o introspectivo contido em tantas obras de Maurice Ravel é visitado, há de se entender o fascínio exercido pelo autor de Miroirs no filósofo-musicólogo em todas as peças em que a exuberância escritural esteja voltada ao pleno domínio técnico instrumental. Dirse-ia que Jankélévitch capta o timbre orquestral dimensionado em peças para piano solo, como exemplo. Em visão voltada à pirotecnia romântica, Jankélévitch afirma: "Encontra-se, sem dúvida, um certo gosto do heroísmo que nosso motejador (ironia da sorte!) herda do Romantismo, as performances de Paganini e as proezas de Liszt" ${ }^{4}$ Este olhar a partir da admiração entusiasta pelas acrobacias lisztianas - Jankélévitch mantinha uma foto de Liszt em seu estúdio-biblioteca - pode-se verificar na sua interpretação literária de Scarbo, terceira das peças de Gaspard de la Nuit, a partir de poemas de Aloysius Bertrand. Hipnotizado pela dimensão, o pensador extravaza: "(...) é como a enciclopédia diabólica de todas as armadilhas, obstáculos, arapucas, que uma imaginação inesgotável pode colocar sob os dedos de um virtuose (...) impossivel para a mão habituar-se: Scarbo pelas suas interrupções brutais, pelas readaptações contínuas impostas ao pianista, rompe todas as enervações musculares à medida que elas se fixam".

Jankélévitch mostra-se plenamente envolvido pela exuberância técnico-pianística do Concert pour la main gauche, L'Alborada del Gracioso, Jeux d'eaux, Noctuelles, Ondine, Une barque sur l'océan... Pormenorizar-se sobremaneira nas peças para piano é decorrência da admiração por Liszt, paradigma da juventude aos decênios posteriores a desvendar os caminhos da performance acrobática.

Entenda-se, pois, que a origem do descortino virtuosístico, liberto, rapsódico, é captada por Jankélévitch pelo fato de ter sido o "século XIX o século da Rapsódia, como ele é o século das nacionalidades" ram, de preferência, da segunda metade do século XIX aos limites dos anos 50 deste. 


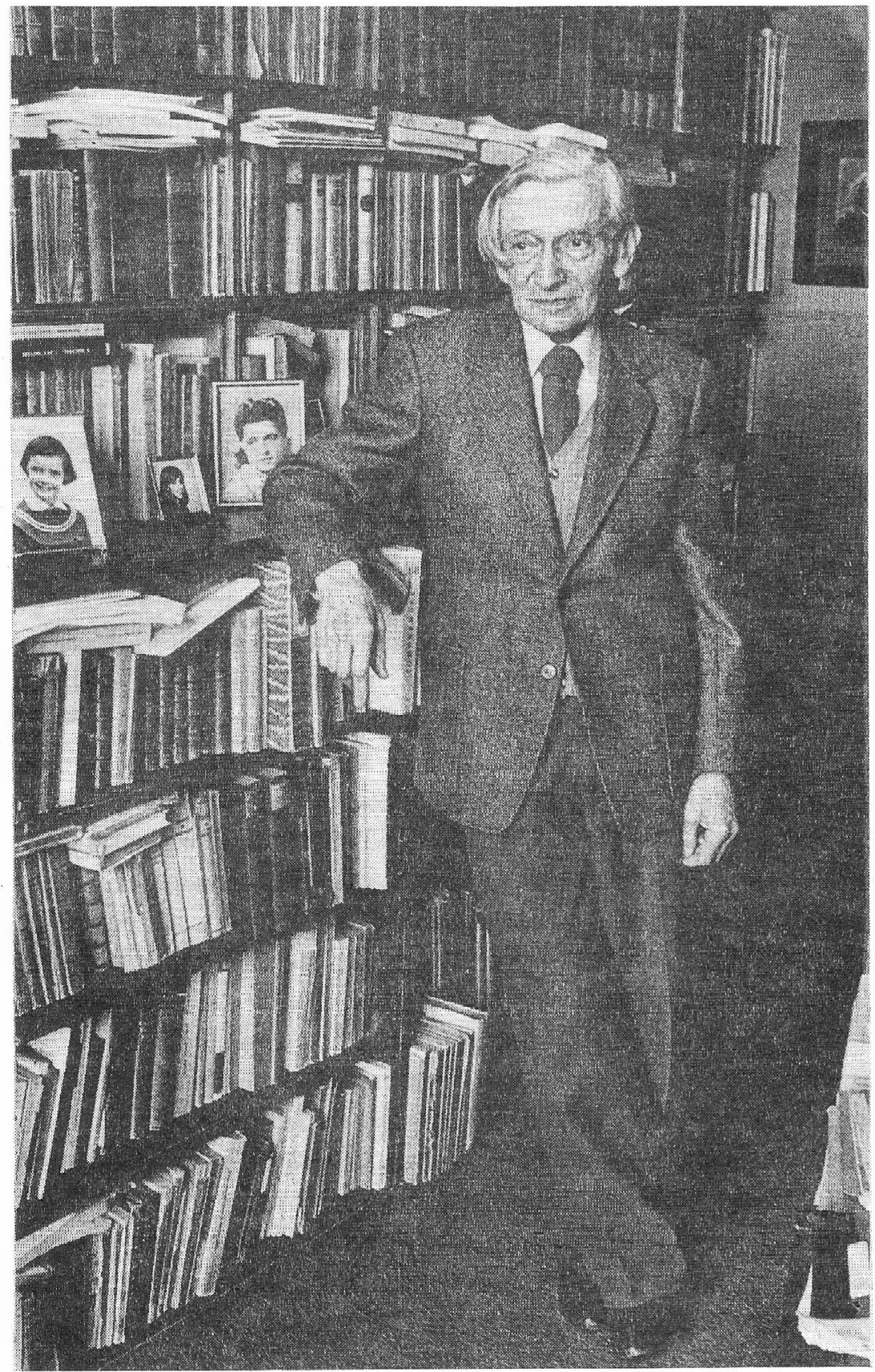


Depreende-se que o espírito romântico, livre, altruístico, egoístico e erótico de Liszt é captado por Jankélévitch através da textura musical que o pensador apreende em seus vários compartimentos, dos quais o da virtuosidade apresenta-se hipnótico: "No virtuosismo de Liszt há um interesse tecnológico ou quirotécnico, ao mesmo tempo que uma homenagem à demiurgia artesã do homem. Nada lhe é impossível (...) tudo o que pode o homem fazer com os seus dez dedos, tudo o que o homem virtuose consegue diante do teclado (...) pois o virtuosismo implica, com o seu corolário, o solisme, que exalta a solidão do herói..."7. Não é dificil compreender, pois, a profunda empatia Liszt-Ravel sedimentada na fulgurância.

Se o autor de Le je-ne-sais-quoi et le Presque rien apreende esse espírito rapsódico e improvisador para buscar a escuta diferenciada nas obras de Rimsky Korsakov, Isaac Albéniz, Déodat de Séverac, autores estudados no livro citado em nota anterior, em Le Nocturne (Paris, Albin Michel, 1957), o mesmo Fauré é revisitado e Chopin tem espaço no universo da noite, assim como Éric Satie na claridade da manhã. Claro e escuro, velado e desvelado, os contrários em harmonia já fixam as raizes até então tênues, que se expandem na produção pós-60. Jankélévitch, que sem amarras deixara-se seduzir pelo canto das sereias - a virtuosidade que hipnotiza - , penetra a ampla floresta das metáforas, dos símbolos, do poético. Classiciza-se a lembrar palavras de François Couperin: j'aime beaucoup mieux ce qui me touche, que ce qui me surprend. ${ }^{8}$

Em La Musique et l'Ineffable (Paris, Armand Colin, 1961), paradigma teórico-imaginário, Jankélévitch questiona, interpreta símbolos, cria alegorias, espalha as senhas de uma renovada visão reflexiva. O filósofo-musicólogo a cada período mais volatiliza o virtuosismo que será, doravante, o das comparações repletas de simbologia. Rende-se ao intrínseco da obra, tendo como ponto de partida o símbolo que o fascina sempre, mas não descartando fatores menos herméticos: o descritivo, o programático e mesmo o imitativo. Outra será a sedução, outras as sereias, sempre a ausência das amarras ou dos ouvidos silenciados. É o que touche, emo- 
ção que evapora da partitura, renovada fonte para as comparações, essencialidade da obra despojada da ornamentação que visa ao surpreender. As metáforas, que se dimensionam sob a ótica da valorização das possibilidades possíveis contidas no resultado final da criação, apresentam-se visualizadas no cume maior de seus estudos singulares: Claude Debussy.

Se escreve, na década de sua morte, entenda-se agora como concentração final, La Présence Lointaine (Paris, Seuil, 1983), onde retornam Albéniz, Séverac e mais Mompou, a penetração no universo de Debussy poderia ser entendida como o interpretar diferenciado de tudo o que anteriormente se escrevera sobre o autor de $\mathrm{LaMer}^{9}$.

Dedica três livros a Debussy. De um primeiro, Debussy et le mystère (Neuchâtel, À ta Baconnière, 1949) a La vie et la mort dans la musique de Debussy (Neuchâtel, À la Baconnière, 1968), aportando em Debussy et le mystère de l'instant (France, Plon, v. 2 "De la musique au silence", 1976), Jankélévitch está sempre a ampliar o espectro da simbologia e o universo debussyniano lhe estaria a despertar a expansão através dos anos. Se repetições conceituais existem, aplicando modelos, em 1976, já expostos sem a mesma amplitude em 1949, há que se entender a preservação de determinados paradigmas. Poder-se-ia acrescentar ser Debussy a exceção entre os compositores estudados pelo pensador, pois desde o primeiro livro sobre o autor de Proses Lyriques, não é o virtuosismo o modelo hipnótico, mas a beleza sonora e o que ela pode sugerir no imaginário.

Entender Debussy sob a visão conceitual de Jankélévitch é permear parcela do possível, é penetrar caminhos até então não percorridos, pré-existentes, muitas vezes camuflados na subjacência da qualidade missivística e nos textos do autor de Estampes.

Em sendo Debussy um compositor que prioriza o sentido da palavra, tendo desde a juventude escolhido textos poéticos de autores que permaneceram, como Verlaine, Baudelaire, Pierre Louÿs, La Forgue, Mallarmé, entre outros, a criação musical estará amalgamada ao verso, dele extraindo o seu conteúdo simbólico. Não 
por acaso Jankélévitch, a fim de tentar explicar a música instrumental sem palavras, busca a comparação no já criado, a partir da palavra ou mesmo nas epígrafes debussynianas, sempre plenas de senhas desveladoras. O universo sonoro de Debussy pode estar contido na amplidão, tanto em Syrinx para flauta solo como na exuberância orquestral dos Nocturnes ou de La Mer.

A interferência de Vladimir Jankélévitch no affaire Debussy consiste na tentativa de compreender o todo compreensível. Os caminhos que levam ao geotropismo, este final absoluto de profundidade: "O geotropismo de Pelléas et Mélisande situa-se primeiramente no segundo ato, quando Mélisande se debruça sobre a beira da fonte dos cegos, como também ao curvar-se, na primeira cena do terceiro ato, na janela da torre; ainda a considerar o mergulho da aliança, imantada pela atraente profundidade, o mergulho dos cabelos que Mélisande deixa cair sobre a água insondável; no terceiro ato, é novamente o peso de uma cabeleira deslizando e, após, a angustiante lição de espeleologia: a descida de Golaud e Pelléas aos subterrâneos do castelo, em direção ao poço e às águas mortas; e, enfim, nos últimos compassos do quarto ato, a queda do firmamento inteiro"10. Contrapondo à descida abissal, a ascensão à luz. A saída de Golaud e Pelléas dos subterrâneos é típica. Tanto nas conceituações geotrópicas ou heliotrópicas, Jankélévitch exemplifica, mostrando nos compassos concernentes as intenções simbolistas de Debussy. Assim nas categorias de escalas ou arpejos ascendentes ou descendentes, ou mesmo funções acordais modulantes em degraus levando a textura musical a regiões mais agudas ou graves, transparência do que deve ser sugerido. Pormenoriza Jankélévitch a qualidade do tratamento musical dado por Debussy, a preferenciar o requinte timbrístico.

É certo que valores musicais e a migração conceitual quase que obsessiva para interpretações do instante, do intervalo, do mistério e do silêncio - ou vice-versa - tenham preocupado colegas da Academia, pois seria a "ética de Jankélévitch baseada sobre uma 'dialética' particular entre instante e intervalo" "1. No instante infinitesimal e no intervalo - sempre passível de expansão - 
Jankélévitch compõe parte de seu sistema não dogmático. Mistério e silêncio são explicados a partir da logicidade do tempo. Distingue o secreto, sujeito ao desvelamento, do mistério insondável, não decifrado, e, nesse campo até minado pela possibilidade da interpretação leviana, Jankélévitch passeia sem receio, apreendendo princípios do não-compreensível, namorando categorias de mistérios, sabendo-os impenetráveis. Não por acaso Debussy et le mystère de 1949 será mais sutil em Debussy et le mystère de l'instant de 1976. A fração do tempo, a menor possível, será preocupação.

Jankélévitch busca expressar o que entende por mistérios, sejam eles da angústia, da volúpia, da morte, da vida, da sensualidade, da natureza interpenetrada, todos presentes na obra de Debussy, imenso catálogo de símbolos e sensações. Empreende uma viagem ao fantástico transfigurado da natureza: nuvens, névoas, tempestades, ventos de várias intensidades, chuva, neve, mar, ondas, fontes, águas estagnadas ou as que refletem, a se contraporem às agitações em movimento contínuo ou aos rodamoinhos, metáfora esta última relativa aos motivos musicais que se repetem rápidos, sem contudo se deslocarem. O universo do símbolo em Debussy - não se descarte o fascínio pelos cabelos femininos - é resgatado nas comparações, e quando o compositor retorna a um tema poético que impulsionará a idéia geradora vertida para criações diferenciadas, mas irmãs na simbologia, Jankélévitch mostrase atento, formulando hipóteses etereamente possíveis. Não desiste jamais de interpretar o insondável criativo, participando do ato da interpretação, essa forma possível de recriação, seja ela literária ou sonora.

Sob a ótica jankélévitchiana, a interpretação literária daquilo que há subjacente na partitura musical, destaca, para que a simbologia seja transmitida, as fontes das dinâmicas, os seus extremos e os extremos no vasto campo dos extremos. Seriam sobremaneira os caminhos em direção ao silêncio, os presque-rien, contrariamente às altas intensidades, a categoria mais pesquisada pelo pensador: "O pianíssimo debussyniano se estabelece não apenas no momento em que o barulho emerge do silêncio, mas também no 
momento em que penetra tal silêncio"12. Silêncio insular, refúgio auditivo, jardim silencioso. Não hesita nessa penetração obsessiva nas mais baixas intensidades, sublinhar o quase inaudivel representado pelos diminuendos precisamente nomeados por Debussy através de singular terminologia, ou à decorrência possível caracterizada pelas pausas longas ou mais longas, a entender o silêncio como princípio da respiração, da vida portanto: "porque a música não respira que no oxigênio do silêncio. $\mathrm{O}$ mesmo com os micro-silêncios, silêncios minutados no interior do silêncio"'13. Esse navegar nas águas dos vários afluentes do silêncio determina a valoração em Debussy desses espaços do inaudivel. Considere-se ter sido o compositor o primeiro a tudo assinalar nos campos da dinâmica, da agógica, da articulação. As aproximações em direção ao nãoaudível, Debussy as faz sobremaneira a partir do início do século, poeticamente. Utiliza-se de terminologia basicamente francesa: en se perdant, en retenant et en s'effaçant, en s'éloignant, encore plus loin et plus lointain, morendo, pp morendo jusqu'à la fin, quittez en laissant vibrer, sourd et en s'éloignant, fronteiras últimas... e o silêncio se instaura. $\mathrm{O}$ silêncio oxigenado é silêncio e "(...) inversamente, como a treva mortal é o negro absoluto e a noite cega, da mesma maneira o silêncio mortal é um silêncio absolutamente mudo. - Silêncio mortal e divino silêncio, eles se opõem um ao outro como Indizível e Inefável"14. Tempo do silêncio, eterno, longo ou micrométrico.

Jankélévitch capta outra determinante na obra de Debussy: o infinitesimal, microparcela do tempo. Vida e Morte estão em confronto permanente no campo da criação e das idéias, em jogo perene. São cúmplices a cada instante, a partir do sentido que se pode dar ao ínfimo e fugidio micro-segundo. O instante infinitesimal após a meia-noite é o caminho da luz, tudo aponta para a esperança, assim como o instante infinitesimal, igualmente, após o meio-dia, a plena luz, a expectativa das trevas, que pode ter como símbolo a morte acalentada, não temida. Seria possível entender-se a temática morte, assustadora pela sua finitude, como uma das mais - senão a mais - freqüentadas por Jankélévitch. Não hesita, inquire, ques- 
tiona a participação do homem, intransferível, experiência única do instante preciso da morte, jamais transmitido. Revela para o momento último a imantação: "O interessado não saberá o segredo de sua própria morte senão no último momento; aquele que vive não sabe a hora senão no instante em que a morte chega, ou seja, no instante em que cessa de viver; pois ele não vive jamais o presente de sua morte, e, por conseqüência, até o instante supremo, ele ignora a data"15. A tragédia que envolve Pelléas e Mélisande, a morte à espreita em textos literários por Debussy musicados, a morte em tantos títulos explícita e implicitamente reservados à obra instrumental, são observadas por Jankélévitch em várias citações, no instante mesmo do acontecido.

A vida como um passeio, metáfora que envolve mistério. $\mathrm{O}$ não saber o instante fatal seria a salvaguarda da suportabilidade. Mors certa, hora incerta. Não haveria uma concretude escatológica. As finitudes microtemporais que levam ao geotrópico ou ao heliotrópico, têm analogias profundas com a vida e a morte. A detectação do idiomático técnico-composicional de Debussy, por Jankélévitch estudado, faz parte do jogo que levará aos antagonismos. "Assim como o homem observa o pórtico indistinto, onde da noite surge o amanhecer, e o momento em que o dia se faz trevas, para surpreender as mensagens da aurora e do crepúsculo, da mesma maneira ele observa apaixonadamente o nascimento e a extinção do barulho para surpreender os segredos da vida e da morte"16.

Se os caminhos dos estudos sobre música tendem, nas últimas décadas, como anteriormente observado, às análises, nas quais o discurso escrito perderia parte essencial de carga paralela ao sonoro, a leitura dos textos de Vladimir Jankélévitch sobre música apreende fundamentos que estariam sendo negligenciados. Indica sentido na comparatividade simbólica e metafórica, seja ela do autor para com o autor ou deste para com seus eleitos. Quando, além do espírito comparativo há o talento do pensador e do poeta, que tenta decifrar intenções possíveis a evidenciar que os sons criados podem ter escutas inefáveis, torna-se lúcido compreender o profundo fascínio que a música exerceu sobre Jankélévitch, que, em 
suas filtrações, revela a leitura sob a ótica enriquecida pelo imaginário. E é a originalidade deste imaginário proposto pelo filósofomusicólogo que leva ao impacto, à reflexão, à polêmica, à aceitação ou discordância, mas não - pareceria claro - ao desinteresse.

\section{NOTAS}

1. Claude Debussy, confessadamente avesso às ideologias germânicas, em plena I Grande Guerra sabe separar sentimentos ao escrever a Jacques Durand, aos 5 de agosto de 1915, a respeito do Ein feste Burg ist unser Gott, um dos símbolos da Alemanha e utilizado pelo compositor na segunda peça do En blanc et noir: "(...) tornou-se ainda mais clara e limpa a atmosfera, dos vapores envenenados emanados durante um instante pelo Coral de Lutero, ou melhor, pelo que ele representa, pois, apesar de tudo, é bonito". Claude DEBUSSY, Lettres de Claude Debussy à son éditeur, Paris, Durand, 1927, p. 143.

2. Cathèrine CLÉMENT, "Le messager du printemps", in Magazine Littéraire, n. ${ }^{\circ} 333$, juin 1995, p. 27.

3. Vladimir JANKÉLÉVITCH, Fauré et l'inexprimable, France, Plon, 1974 , p. 315.

4. IDEM, Maurice Ravel, Paris, Rieder, 1939, p. 70.

5. IDEM, ibidem, p. 73.

6. IDEM, La Rapsodie - verve et improvisation musicale, Paris, Flammarion, 1955, p. 6.

7. IDEM, ibidem, p. 46.

8. François COUPERIN, "Prefácio" à edição de 1713 de Pièces de clavecin (Livre I), Paris, Durand, 1966, p. II.

9. O compartimento mais objetivo a respeito de um autor refere-se à edificação da sua trajetória. Nesse mister, os biógrafos Léon Vallas, Edward Lockspeiser e Marcel Diétschy deixaram obras fundamentais. Mais recentemente, François Lesure, tendo publicado tomos contendo missivas, textos e documentos referenciais inéditos de Debussy; participando como coordenador da monumental edição crítica de suas obras em longo curso, recentemente, em Claude Debussy - biographie critique, Paris, Klincksieck, 1994, apresenta o mais abrangente estudo através das fontes mais fidedignas que fizeram demolir inúmeras lendas sobre o autor de $L a$ Mer, assim como possibilita a total reformulação de muitas "antigas" certezas.

10. Vladimir JANKÉLÉVITCH, Debussy et le mystère de l'instant - De la musique au silence, v. 2, France, Plon, 1976, p. 97-98. 
11. Carlo MIGLIACCIO, "Bergson pour maître", in Magazine Littéraire, op. cit., p.37.

12. Vladimir JANKÉLÉVITCH, La vie et la mort dans la musique de Debussy, Neuchâtel, À la Baconnière, 1968, p. 114.

13. IDEM, La musique et l'ineffable, Paris, Du Seuil, 1983, p. 168.

14. IDEM, La mort, France, Flammarion, 1977, p. 83.

15. IDEM, ibidem, p. 135.

16. IDEM, La musique et l'ineffable, Paris, Seuil, 1983, p. 176.

José Eduardo Martins é Pianista e Professor do Departamento de Música da Universidade de São Paulo. 